\title{
Performance Analysis of Animal Migration Optimization Algorithm in Extracting Solar Cell Double Diode Model Parameters
}

\author{
Mohamad Nor Othman, ${ }^{1,2,}$, Baharudidn Ismail, ${ }^{2,3}$, Zainuddin Mat Isa ${ }^{2}$ \\ ${ }^{1}$ Suruhanjaya Tenaga, Wisma Perkeso, Melaka, Malaysia \\ ${ }^{2}$ School of Electrical System Engineering, Universiti Malaysia Perlis, Perlis, Malaysia \\ ${ }^{3}$ Centre of Excellence for Renewable Energy (CERE), School of Electrical System Engineering, Universiti Malaysia Perlis, Perlis, \\ Malaysia
}

Received July 31, 2019; Revised December 25, 2019; Accepted December 27, 2019

Copyright $\bigcirc 2019$ by authors, all rights reserved. Authors agree that this article remains permanently open access under the terms of the Creative Commons Attribution License 4.0 International License

\begin{abstract}
Modeling solar cell involved the formulation of the current versus voltage ( $\mathrm{I}-\mathrm{V}$ ) non-linear curve. Obtaining the accurate model parameters value is important for better performance evaluation, simulation and control of solar cell and module. Extracting these values using traditional methods required more resources, therefore, the used of meta heuristic optimization method become an attractive choice. Some optimization algorithms have been used to estimate the model parameters. However, more investigation is needed to improve model estimation. In this paper, the performance of Animal Migration Optimization (AMO) technique in identifying the unknown parameters of solar cell double diode model is studied. A measurement data of a $57 \mathrm{~mm}$ diameter commercial (R.T.C. France) silicon solar cell is used to observe the performance of this algorithm and the consistency of accurately estimating various parameters. The results show that the estimated and experimental data are accurately fitted and certify a good agreement. Furthermore, comparative study among different parameter estimation techniques is presented to demonstrate the effectiveness of the proposed approach.
\end{abstract}

Keywords Animal Migration Optimization, Double Diode Model, Solar Cell Model, Parameter Extraction

\section{Introduction}

Modeling the solar cell involves the formulation of the non-linear current vs. voltage $(I-V)$ curve. The single diode model (SDM) and double diode model (DDM) are commonly used to describe this relationship [1]. The saturation current, ideality factor, generated photocurrent, series and shunt resistance are the main parameters that describe the models behaviour of solar cell. Determining the accurate value of these parameters leads to better performance evaluation, simulation and control of solar cell and solar module [1, 2].

Metaheuristic optimization has gained enormous attention as a method for solving engineering problems such as extracting the fuel cell parameters [3, 4], determining the angle for multilevel inverter switching pattern [5, 6], obtaining the MPPT parameters [7, 8], solving the ED [9] and determining the solar cell parameters [1, 10-14]. In determining the solar cell parameters, Oliva, D. et. all. [13] purposed an improved version of Whale Optimization algorithm (WOA) known as Chaotic Whale Optimization algorithm (CWOA) to estimate the solar module parameters. They used the chaotic Singer map to improve the performance of WOA. As a result, the performance of proposed algorithm surpasses many reported algorithms such as the Bird Mating Optimizer (BMO) and Simplified Teaching-Learning Based Optimization (STLBO). Elaziz, M.A and Oliva, D. [11] also proposed another variant of WOA to extract the solar cell and module parameters. They called the Opposition Based Whale Optimization algorithm (OBWOA). This algorithm also shows great performance when comparing with other algorithms.

Moreover, Farhana et. all. [1] proposed hybrid method between Particle Swarm Optimization and Nelder-Mead(NM-PSO) to determine the solar cell and module parameters. This algorithm surpasses the BMO when comparing their performance. Other than that, there are many metaheuristics algorithms have been used to study their performance in extracting the solar cell model 
parameters such as improved JAYA optimization algorithm (IJAYA) [14], Ant Lion Optimizer (ALO) [10] and Hybrid Flower Pollination algorithm (GOFPANM) [12].

In this paper, the performance of AMO in extracting the solar cell parameters is being studied. The proposed algorithm is used to determine the double diode model parameters of $57 \mathrm{~mm}$ France [11] solar cell. Furthermore, the best result is then being compared with other methods reported in the literature to observe the performance of AMO. The rest of this paper is structured as follows: Preliminaries Section presents the problem formulation of DDM. In Animal Migration Optimization Section, the operation of AMO is described. In Results and Analysis Section, the obtained results are analysed and compared with other optimization methods. Finally, the conclusion is drawn in Conclusions Section.

\section{Preliminaries}

This section described the mathematical formulation of Double Diode Model (DDM) used in this work, followed by the description of the objective function.

\subsection{Mathematical Formulation of DDM}

A solar cell double diode model equivalent circuit is shown in Figure 1. This model (with $R_{p}$ and $R_{s}$ ) has been proposed by many researchers [1, 11-15]. The output current $I_{s}$ of the cell is given as:

$$
\mathrm{I}_{\mathrm{s}}=\mathrm{I}_{\mathrm{ph}}-\mathrm{I}_{\mathrm{d} 1}-\mathrm{I}_{\mathrm{d} 2}-\mathrm{I}_{\mathrm{Rp}}
$$

where $I_{p h}$ is the photo-generated current, $I_{d 1}$ and $I_{d 2}$ are the first and second diode current, correspondingly, and IRp is the shunt resistor current. Using the Shockley equation for the diode currents and substituting the current of the shunt resistor, 1 can be rewritten as following equation:

$$
I_{8}=I_{\mathrm{ph}}-I_{o 1}\left[\exp \frac{V_{8}+I_{8} R_{8}}{a_{1} V_{t}}\right]-I_{o 2}\left[\exp \frac{V_{8}+I_{8} R_{8}}{a_{2} V_{t}}\right]-\frac{V_{8}+I_{8} R_{8}}{R_{p}}
$$

where $I_{o 1}$ and $I_{o 2}$ are the diffusion and saturation currents of diode 1 and diode 2, respectively, $V s$ is the solar cell output voltage, $a_{1}$ and $a_{2}$ are the diode ideality factor and $V t$ represents the thermal voltage which is given as:

$$
V_{t}=\frac{k T}{q}
$$

The parameter $k$ is the Boltzmann constant $\left(1.3806503 \times 10^{-23} \mathrm{~J} / \mathrm{K}\right), \mathrm{q}$ is the electron charge $\left(1.60217646 \times 10^{-19} \mathrm{C}\right)$ and $T$ is the temperature of the solar cell in Kelvin (K). In order to reflect the solar cell performance as well as that of the actual system, the identification of the parameter is important. For further simplification, several researchers assumed $a_{1}=1$ and $a_{2}=$ $2[16,17]$.

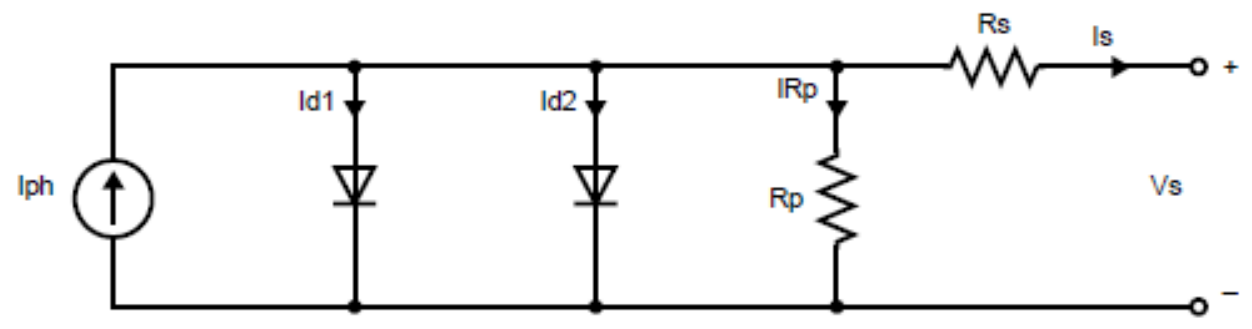

Figure 1. Double diode model equivalent circuit. 


\subsection{Problem Formulations}

The solar cell parameters for different models from IV can be extracted using the optimization algorithms.

In DDM, there are 7 unknown parameters, namely, $I_{p h}$, $I_{o 1}, I_{o 2}, R_{p}, R_{s}, a_{1}$ and $a_{2}$ as shown in equation 2. Before continuing with the optimization operations, an objective function should be defined. In this work, the root mean square error (RMSE) between the output current of the actual solar cell and the model output current is chosen as the objective function [1]:

$$
R M S E=\sqrt{\frac{1}{N} \sum_{i=1}^{N}\left(I_{s i, m}-I_{s i}\right)^{2}}
$$

where $I_{s i}, m$ is the measured output current of the actual solar cell, Isi is the model output current, and $N$ is the number of the experimental data point. During the optimization process, the objective function is minimized with respect to the parameters range. The upper and lower boundaries of the parameters, used by most researcher in the literature $[1,11,12,14]$, are shown in Table 1 . The model parameters are continuously adjusted by the optimization algorithm, until a termination criterion is met (basically set by the number of iteration). The aim is to minimize the objective function.

Table 1. Upper and lower range of the solar cell parameters

\begin{tabular}{ccc}
\hline Parameter & Lower & Upper \\
\hline \hline$I_{p h}(\mu A)$ & 0 & 1 \\
$I_{o}(\mu A)$ & 0 & 1 \\
$R_{s}(\Omega)$ & 0 & 0.5 \\
$R_{p}(\Omega)$ & 0 & 100 \\
$a$ & 1 & 2 \\
\hline
\end{tabular}

\section{Animal Migration Optimization algorithm}

There are two main processes in AMO algorithm which are the migration process and population updating process [18-20]. In this algorithm, itstarts with random initialization of a set of $N_{p}$ animal positions. Each animal position, $x_{i}$ is a feature vector with $D_{x}$ dimension, which is uniformly distributed between the lower initial parameter bound $a$ and the upper initial parameter bound $b$. Therefore, the initialization of the $j$ th component of the ith vector can be written as:

$$
x_{i, j}=a_{j}+\operatorname{rand}_{i, j}\left(b_{j}-a_{j}\right), i=1, \ldots, N_{p}, j=1, \ldots, D_{x}
$$

where $\operatorname{rand}_{i, j}$ is a uniformly distribution random number between 0 and 1 .

\subsection{Migration Process}

In migration process, the algorithm simulates behaviours of animal groups moving to a new position. The new positions of individuals are determined based on the direction of animal movement, where they must follow three migration rules[18-20]: 1) moving in the same direction as its neighbours; (2) remaining close to its neighbours; (3) avoiding collisions with its neighbours. Then, the individual position is updated according to the positions of their neighbours using the following formula:

$$
x_{i_{G+1}}=x_{i_{G}}+\delta\left(x_{\text {neighbourhood }_{G}}-x_{i_{G}}\right)
$$

where $x_{i G+1}$ is the new position of the ith individual, $x_{i G}$ is the current position of the ith individual, $\delta$ is produced using a random number generator controlled by a Gaussian distribution, and $x_{\text {neighbourhood }}$ is the current position of the randomly selected neighbourhood.

\subsection{Population Updating Process}

In this process, the algorithm simulates how some animals leave the group and new animals join in the new population. Assuming the number of available animals is fixed, individuals will be replaced by some new animals with probability according to the quality of the fitness. The probability of the individual with best fitness is set to 1 , and the probability of the individual with worst fitness, is set to $1 / N p$. This process can be shown as follows:

$$
\begin{aligned}
& \text { for } i=1 \text { to } N \\
& \text { for } j=1 \text { to } D \\
& \text { if } \text { rand }>P_{a} \\
& \quad x_{i_{G+1}}=x_{r i_{G}}+\text { rand. }\left(x_{\text {best }_{G}}-x_{i_{G}}\right) \\
& \quad+\text { rand. }\left(x_{r 2_{G}}-x_{i_{G}}\right) \\
& \quad \text { end if } \quad \\
& \text { end for } \\
& \text { end for }
\end{aligned}
$$

where $r_{1}, r_{2}=\in[1, \ldots, N]$ are randomly chosen integers, and $r_{1} \neq r_{2} \neq=i$. The fitness of new solution $x_{i G+1}$ will be evaluated and compared with the fitness of $X_{i G}$. The individual with a better objective fitness is chosen. The standard AMO algorithm can be described as the followings [20]: 


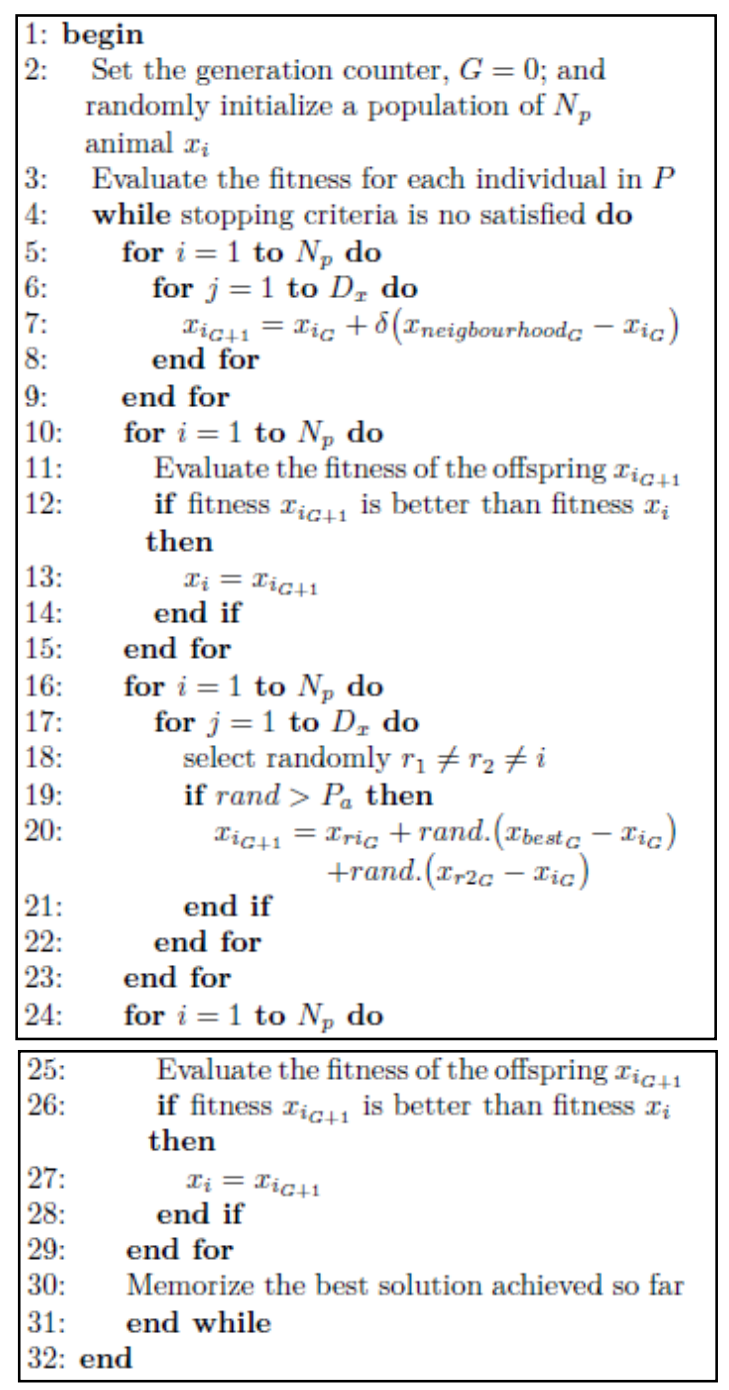

\section{Results and Analysis}

In this section, the results of the application of AMO for estimating the DDM parameters of experimental $I-V$ data collected from a $57 \mathrm{~mm}$ diameter commercial (R.T.C France) silicon solar cell under standard test conditions will be presented and analysed. The data for RTC France are taken from [11] and are widely used in the literature to test their algorithm [1, 11, 12, 14, 21]. The performance of AMO is validated by comparing with a couple of state of the art algorithms including the Improved Opposition-Based Whale Optimization algorithm (OBWOA)[11], improved JAYA optimization algorithm
(IJAYA) [14], Hybrid Flower Pollination algorithm (GOFPANM) [12] and, Hybrid Nelder-Mead And Modified Particle Swarm Optimization (NM-MPSO) [1]. The compared algorithms have been run for 50 times. The population size is set to be 150 and the maximum number of iteration is 10000 which is similar with [11]. All the simulation work, presented in this paper, made use of MATLABR 2015a environment, working at Intel $\mathrm{R}$ CoreTMi5 CPU, $2.5 \mathrm{GHz}$ and 4 GB RAM.

\subsection{Performance Analysis}

In this subsection, the performance analysis of AMO in estimating DDM parameters of RTC France silicon solar cell at $33^{\circ} \mathrm{C}$ and full sun (irradiation of $1000 \mathrm{~W} / \mathrm{m}^{2}$ ) is presented. As stated in the problem formulation section, in the DDM, the number of decision variables is seven. The AMO has been run for 50 times and the best objective value of each run is shown in Figure 2. Observing this figure, the best, mean and worst objective values are 1.043 $\times 10^{-3}, 1.0 \times 10^{-3}$ and $9.8545 \times 10^{-4}$ respectively. Over the 50 runs, only 18 times the best objective values are above mean value and the rest are below it. The standard deviation value is $1.4104 \times 10^{-5}$ which is low and indicating the consistency of the algorithm optimizing the model parameters. The convergence curve for the best objective value is plotted in Figure 3. Looking at this figure, the AMO starts to produce lower objective value after 100 iterations and obtained the relative stability of the objective value after 3000 iterations. Other than that, this curve also shows that the algorithm stag at local optima recovers from it for few times along the way to final iterations. This proves the robustness of the algorithm. To further assess the reliability of the AMO, the I-V curve and the P-V curve fitting is drawn between calculated and measurements as illustrated in Figure 4 and Figure 5, correspondingly. These figures show that the estimated and the experimental data are accurately fitted and certify a good agreement. Furthermore, both of the individual absolute error (IAE) and the relative error (RE) are used to evaluate the error among the estimated and measured data. These two indexes are respectively defined by equations 7 and 8:

$$
\begin{gathered}
I A E=\left|I_{i, m}-I_{i}\right| \\
R E=\frac{I_{i, m}-I_{i}}{I_{i, m}}
\end{gathered}
$$




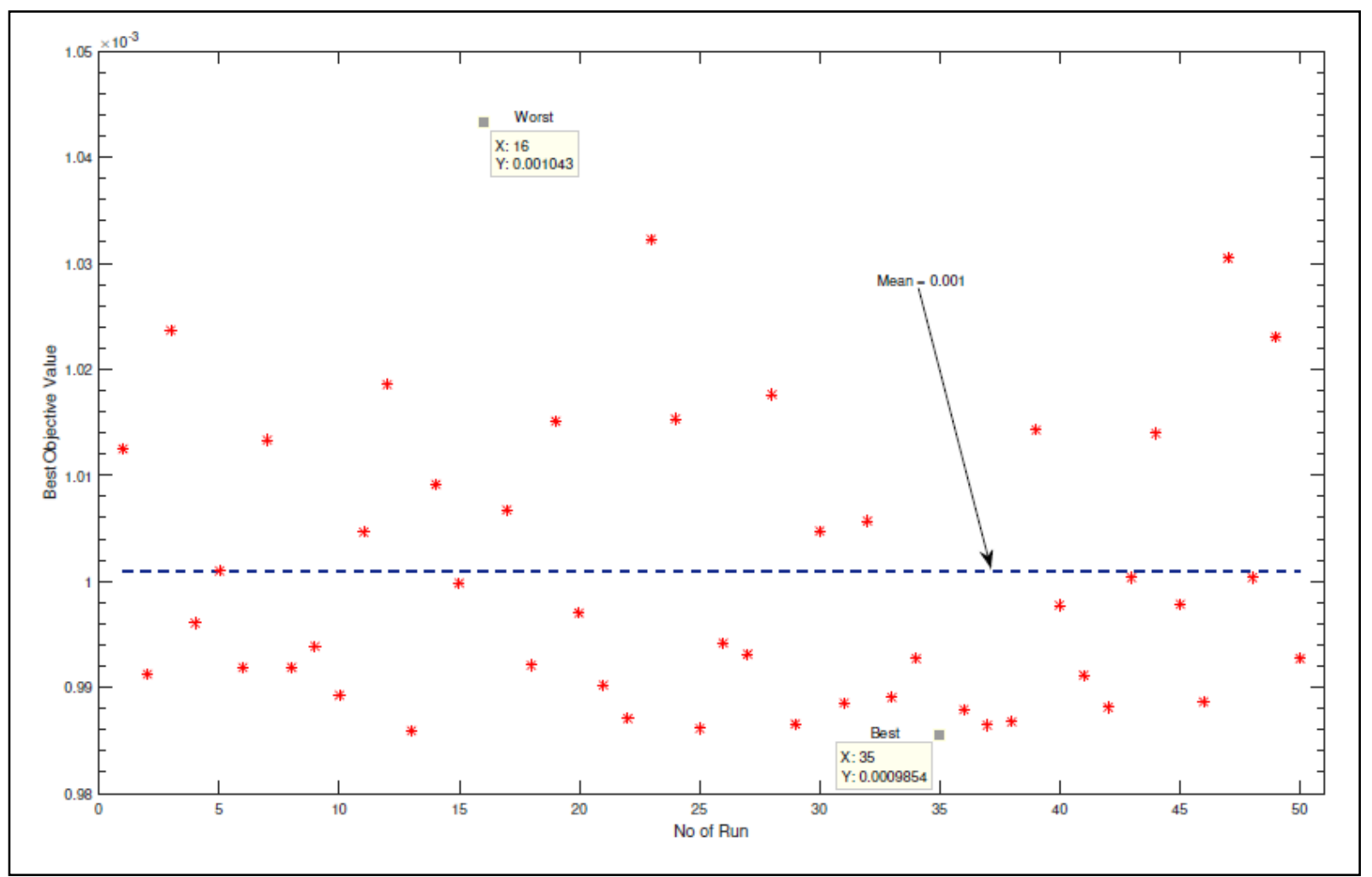

Figure 2. The best objective value distributions for 50 trial runs

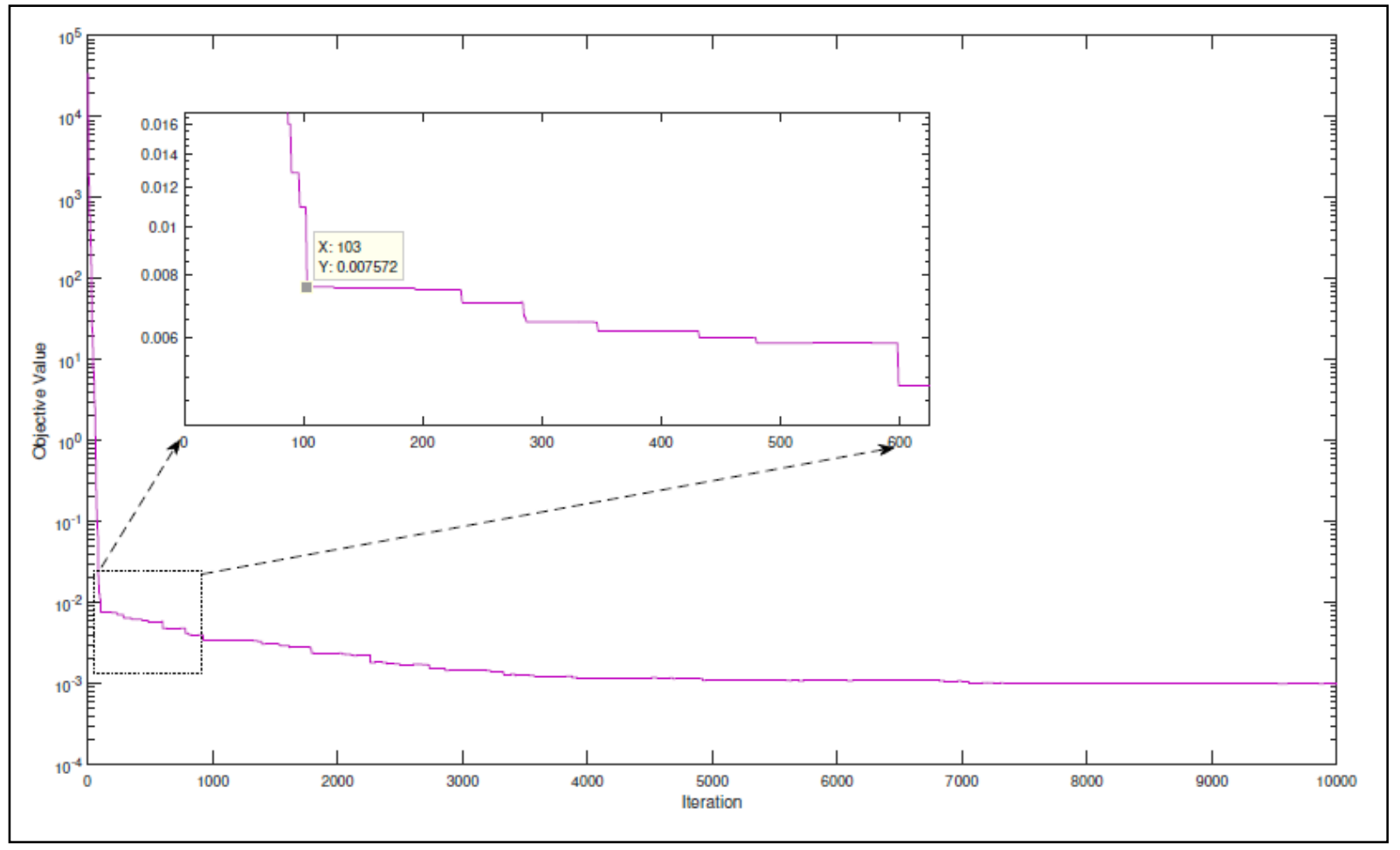

Figure 3. The best objective value convergence curve 


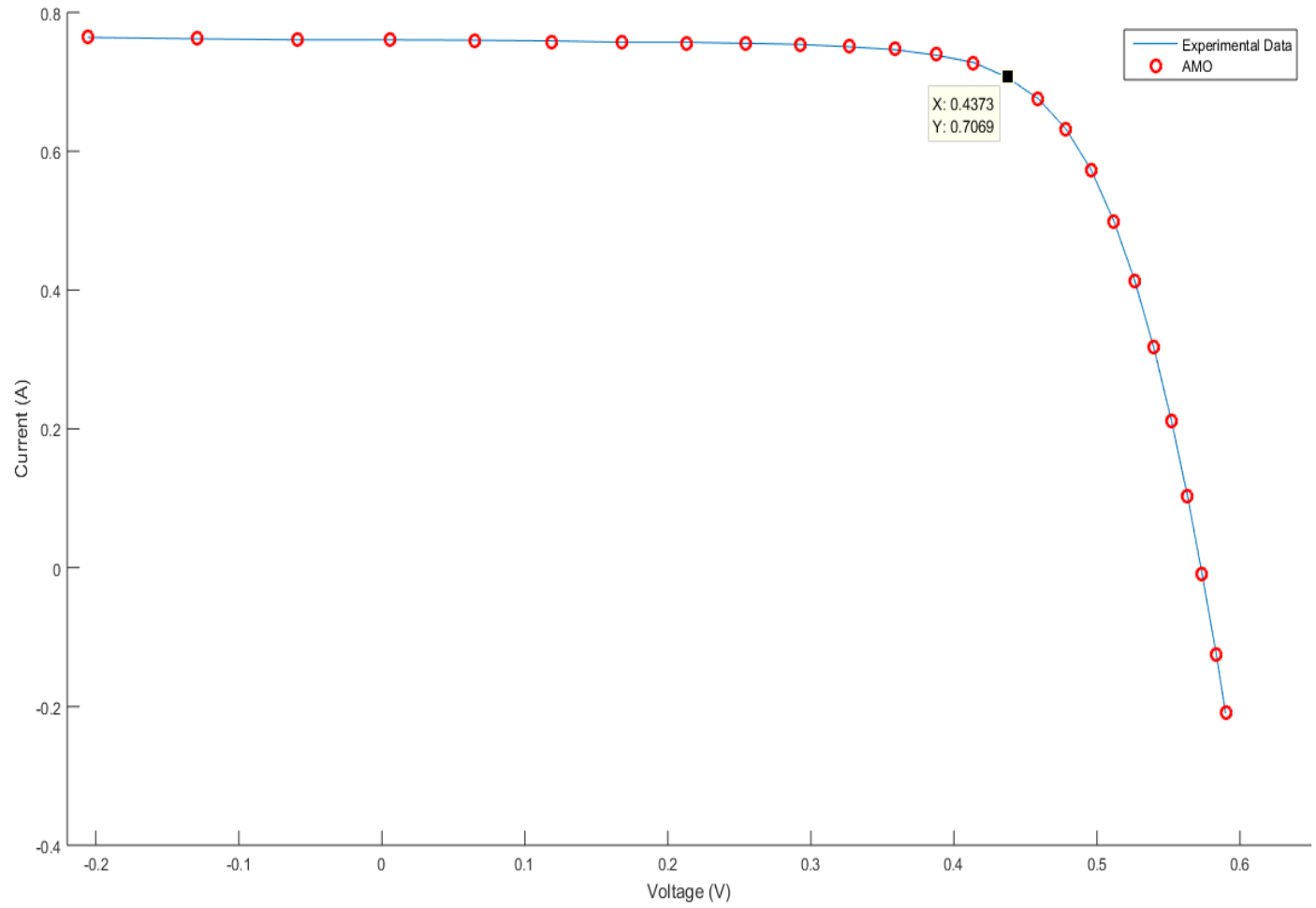

Figure 4. $\quad I-V$ curve

The experimental and calculated data along with the IAE and the RE are given in table 2 . The IAE values are less than $1.37 \times 10^{-3}$ and the RE values are within the range of $-2.095 \times 10^{-3}$ to $7.2050 \times 10^{-2}$. These prove that the calculated data from the estimated optimal parameters of AMO are in consistent with the experimental data.

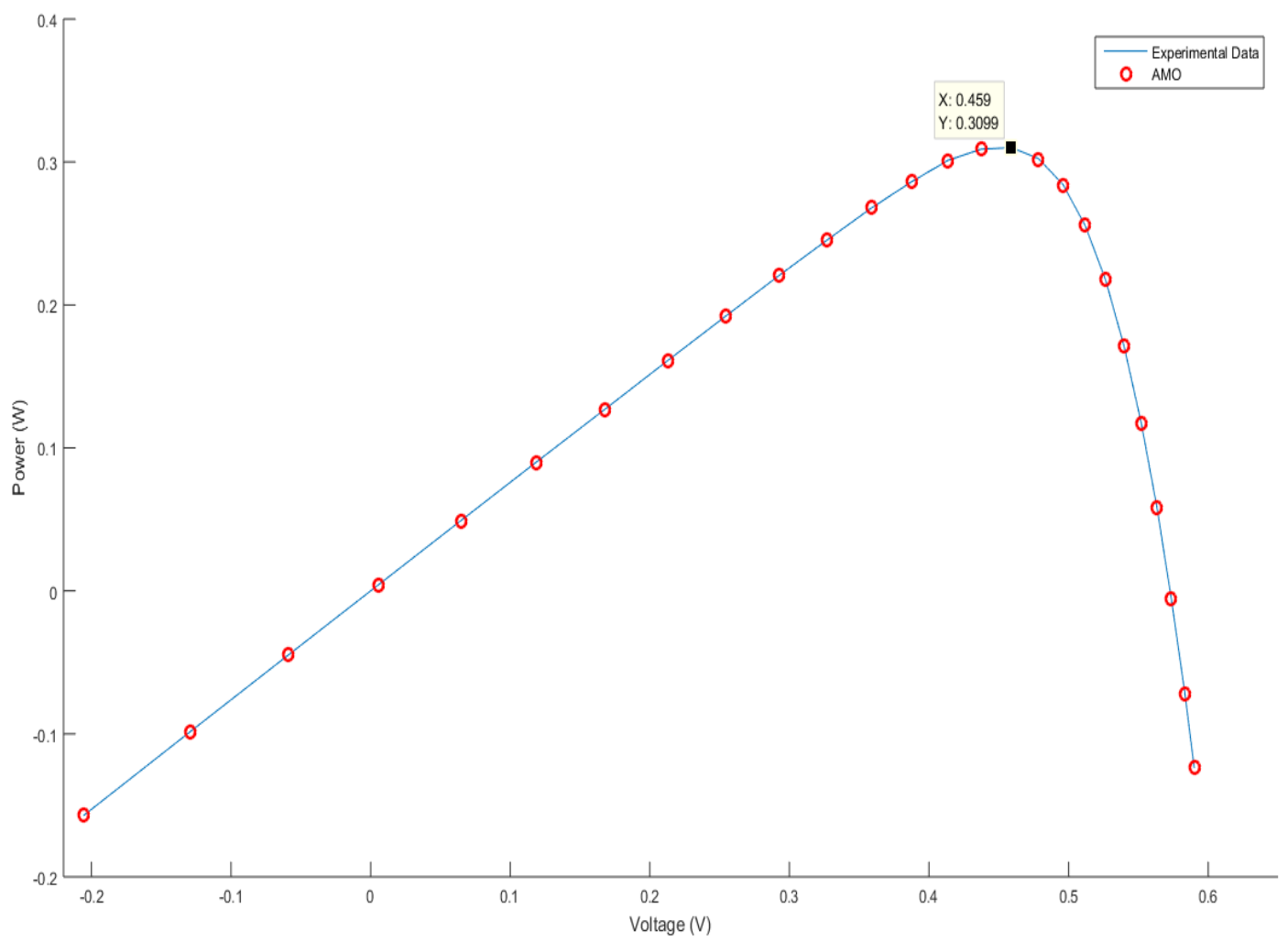

Figure 5. $P-V$ curve. 
Table 2. Relative error and individual absolute error for each measurement

\begin{tabular}{|ccrrc|}
\hline \hline Data & $I_{\text {measured }}(A)$ & $I_{\text {calculated }}(A)$ & \multicolumn{1}{c}{ RE } & IAE \\
\hline 1 & 0.764000 & 0.764065 & -0.000085 & 0.000065 \\
2 & 0.762000 & 0.762648 & -0.000851 & 0.000648 \\
3 & 0.760500 & 0.761348 & -0.001115 & 0.000848 \\
4 & 0.760500 & 0.760154 & 0.000455 & 0.000346 \\
5 & 0.760000 & 0.759061 & 0.001235 & 0.000939 \\
6 & 0.759000 & 0.758052 & 0.001248 & 0.000948 \\
7 & 0.757000 & 0.757103 & -0.000136 & 0.000103 \\
8 & 0.757000 & 0.756153 & 0.001119 & 0.000847 \\
9 & 0.755500 & 0.755092 & 0.000539 & 0.000408 \\
10 & 0.754000 & 0.753659 & 0.000452 & 0.000341 \\
11 & 0.750500 & 0.751368 & -0.001156 & 0.000868 \\
12 & 0.746500 & 0.747311 & -0.001087 & 0.000811 \\
13 & 0.738500 & 0.740047 & -0.002094 & 0.001547 \\
14 & 0.728000 & 0.727342 & 0.000904 & 0.000658 \\
15 & 0.706500 & 0.706905 & -0.000573 & 0.000405 \\
16 & 0.675500 & 0.675260 & 0.000355 & 0.000240 \\
17 & 0.632000 & 0.630863 & 0.001799 & 0.001137 \\
18 & 0.573000 & 0.572066 & 0.001630 & 0.000934 \\
19 & 0.499000 & 0.499468 & -0.000938 & 0.000468 \\
20 & 0.413000 & 0.413454 & -0.001099 & 0.000454 \\
21 & 0.316500 & 0.317163 & -0.002095 & 0.000663 \\
22 & 0.212000 & 0.212038 & -0.000181 & 0.000038 \\
23 & 0.103500 & 0.102664 & 0.008080 & 0.000836 \\
24 & -0.010000 & -0.009280 & 0.072050 & 0.000720 \\
25 & -0.123000 & -0.124363 & -0.011081 & 0.001363 \\
26 & -0.210000 & -0.209125 & 0.004168 & 0.000875 \\
\hline Mean & & & 0.002752 & $\mathbf{0 . 0 0 4 4 8 2}$ \\
\hline \hline
\end{tabular}

\section{Conclusions}

The solar cell parameter estimation is a multimodal optimization problem with multiple local optima. In multimodal problems, meta heuristic algorithms are more likely to converge to local optima, due to their premature convergence problem. In this paper, performance of the AMO in extracting the parameters for DDM is investigated. An RTC France silicon solar cell has been used as the case study of this research. The findings show that the AMO can extract the parameters of DDM and produce good results. However, it cannotsurpass all the other compared with algorithms including the OBWOA, IJAYA, GOFPANM and NM-PSO. This is due to stagnation problem and early convergence issue and clearly can be seen at the convergence curve. Therefore, it is necessary to improve the exploration and exploitation capability of the algorithm. With this improvement, it will improve the efficiency, accuracy and reliability by decreasing the mean error, relative error, standard deviation and average objective values while increasing the success rate value.

\section{REFERENCES}

[1] N. Farhana, A. Hamid, A. Rahim, and J. Selvaraj, "Solar cell parameters identification using hybrid Nelder-Mead and modified particle swarm optimization,” J. Renew. Sustain. Energy, vol. 015502, no. 8, pp. 1-22, 2016.

[2] N. F. Abdul Hamid, N. A. Rahim, and J. Selvaraj, "Solar cell parameters extraction using particles warm optimization algorithm,” in IEEE Conf. Clean Energy Technol., pp. 461465, 2013.

[3] Z. Isa and N. Rahim, "PEM fuel cell model parameters optimization using modified particle swarm optimization algorithm,” in IEEE Conf. Clean Energy Technol., 2013.

[4] N. Hamal, Z. Isa, N. Nayan, M. Arshad, and N. Kajaan, "Optimizing PEMFC model parameters using dragonfly algorithm: a performance study," in 5th IET Int. Conf. Clean Energy Technol., pp. 59 (8 pp.)- 59 (8 pp.), Institution of Engineering and Technology, 2018.

[5] B. Ismail, S. Idris, A. R. Haron, and A. Azmi, "Selective 
Harmonic Elimination of Five-level Cascaded Inverter Using Particle Swarm Optimization,” Int. J. Eng. Technol., vol. 5, no. 6, pp. 5220-5232, 2014.

[6] B. Ismail, S. I. S. Hassan, R. C. Ismail, A. Azmi, and M. H. Arshad, "Elimination of lower order harmonics in multilevel cascaded inverters with equal DC sources using PSO,” Int. Rev. Model. Simulations, vol. 7, no. 4, pp. 554560, 2014.

[7] M. F. N. Tajuddin, S. M. Ayob, and Z. Salam,“"Tracking of Maximum Power Point in Partial Shading Condition using Differential Evolution ( DE ),” in IEEE Int. Conf. Power Energy, no. December, pp. 2-5, 2012.

[8] M. F. N. Tajuddin, S. M. Ayob, Z. Salam, and M. S. Saad, "Evolutionary based maximum power point tracking technique using differential evolution algorithm,” Energy Build., vol. 67, pp. 245-252, 2013.

[9] S. R. Rahim, I. Musirin, M. M. Othman, and M. H. Hussain, "Multiple DG planning considering distribution loss and penetration level using EMEFA-ANN method,” Indones. J. Electr. Eng. Comput. Sci., vol. 7, no. 1, pp. 1-8, 2017.

[10] G. Kanimozhi and Harish Kumar, "Modeling of solar cell under different conditions by Ant Lion Optimizer with LambertW function,” Appl. Soft Comput. J., vol. 71, pp. 141-151, 2018.

[11] M. Abd Elaziz and D. Oliva, "Parameter estimation of solar cells diode models by an improved oppositionbased whale optimization algorithm,” Energy Convers. Manag., vol. 171, no. September 2017, pp. 1843-1859, 2018.

[12] S. Xu and Y. Wang, "Parameter estimation of photovoltaic modules using a hybrid flower pollination algorithm," Energy Convers. Manag., vol. 144, pp. 53- 68, 2017.

[13] D. Oliva, M. Abd El Aziz, and A. Ella Hassanien, "Parameter estimation of photovoltaic cells using an improved chaotic whale optimization algorithm," Appl. Energy, vol. 200, pp. 141-154, 2017.

[14] K. Yu, J. J. Liang, B. Y. Qu, X. Chen, and H. Wang, "Parameters identification of photovoltaic models using an improved JAYA optimization algorithm,” Energy Convers. Manag., vol. 150, no. August, pp. 742-753, 2017.

[15] P. Lin, S. Cheng, W. Yeh, Z. Chen, and L. Wu, "Parameters extraction of solar cell models using a modified simplified swarm optimization algorithm,” Sol. Energy, vol. 144, pp. 594-603, 2017.

[16] K. Ishaque, Z. Salam, and H. Taheri, "Modeling and simulation of photovoltaic (PV) system during partial shading based on a two-diode model,” Simul. Model. Pract. Theory, vol. 19, pp. 1613-1626, aug 2011.

[17] K. Ishaque, Z. Salam, and H. Taheri, "Simple, fast and accurate two-diode model for photovoltaic modules," Sol. Energy Mater. Sol. Cells, vol. 95, pp. 586- 594, feb 2011.

[18] Y. Cao, X. Li, and J. Wang, "Opposition-based animal migration optimization,” Math. Probl. Eng., vol. 2013, 2013.

[19] D. Singh, “Modified Animal Migration Optimization Algorithm for Numerical Function Optimization,” Int. J. Comput. Sci. Inf. Technol., vol. 7, no. 2, pp. 570-574, 2016.
[20] X. Li, J. Zhang, and M. Yin, “Animal migration optimization: An optimization algorithm inspired by animal migration behavior,” Neural Comput. Appl., vol. 24, no. 7-8, pp. 1867-1877, 2014.

[21] T. Easwarakhanthan, J. Bottin, I. Bouhouch, and C. Boutrit, "Nonlinear Minimization Algorithm for Determining the Solar Cell Parameters with Microcomputers,” Int. J. Sol. Energy, vol. 4, no. 1, pp. 1-12, 1986. 